\title{
ARTICLE \\ Anti-SARS-CoV-2 activities in vitro of Shuanghuanglian preparations and bioactive ingredients
}

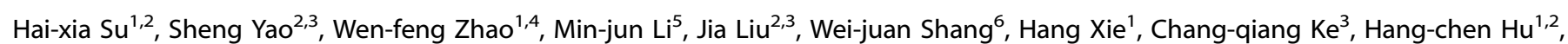
Mei-na Gao ${ }^{1,2}$, Kun-qian Yu ${ }^{1,2}$, Hong Liu ${ }^{2,3}$, Jing-shan Shen ${ }^{1,2}$, Wei Tang ${ }^{1,2}$, Lei-ke Zhang ${ }^{6}$, Geng-fu Xiao ${ }^{6}$, Li Ni ${ }^{7}$, Dao-wen Wang ${ }^{7}$, Jian-ping Zuo ${ }^{2,3}$, Hua-liang Jiang ${ }^{1,2,8}$, Fang $\mathrm{Bai}^{8}$, Yan $\mathrm{Wu}^{6}$, Yang $\mathrm{Ye}^{2,3,9}$ and $\mathrm{Ye}$-chun $\mathrm{Xu}^{1,2}$

Human infection with severe acute respiratory syndrome coronavirus 2 (SARS-CoV-2) causes coronavirus disease 2019 (COVID-19) and there is no cure currently. The $3 \mathrm{CL}$ protease (3CLpro) is a highly conserved protease which is indispensable for CoVs replication, and is a promising target for development of broad-spectrum antiviral drugs. In this study we investigated the anti-SARS-CoV-2 potential of Shuanghuanglian preparation, a Chinese traditional patent medicine with a long history for treating respiratory tract infection in China. We showed that either the oral liquid of Shuanghuanglian, the lyophilized powder of Shuanghuanglian for injection or their bioactive components dose-dependently inhibited SARS-CoV-2 3CLpro as well as the replication of SARS-CoV-2 in Vero E6 cells. Baicalin and baicalein, two ingredients of Shuanghuanglian, were characterized as the first noncovalent, nonpeptidomimetic inhibitors of SARS-CoV-2 3CLpro and exhibited potent antiviral activities in a cell-based system. Remarkably, the binding mode of baicalein with SARS-CoV-2 3CLpro determined by X-ray protein crystallography was distinctly different from those of known 3CLpro inhibitors. Baicalein was productively ensconced in the core of the substrate-binding pocket by interacting with two catalytic residues, the crucial S1/S2 subsites and the oxyanion loop, acting as a "shield" in front of the catalytic dyad to effectively prevent substrate access to the catalytic dyad within the active site. Overall, this study provides an example for exploring the in vitro potency of Chinese traditional patent medicines and effectively identifying bioactive ingredients toward a specific target, and gains evidence supporting the in vivo studies of Shuanghuanglian oral liquid as well as two natural products for COVID-19 treatment.

Keywords: SARS-CoV-2; 3CL protease; traditional Chinese medicines; Shuanghuanglian oral liquid; baicalin; baicalein

Acta Pharmacologica Sinica (2020) 41:1167-1177; https://doi.org/10.1038/s41401-020-0483-6

\section{INTRODUCTION}

Coronaviruses (CoVs; subfamily Coronavirinae, family Coronaviridae, order Nidovirales) are a group of highly diverse, enveloped, positive-sense, single-stranded RNA viruses and are prevalent pathogens that are responsible for a wide range of diseases in animals as well as humans [1, 2]. Human CoV strains, including 229E, NL63, OC43, and HKU1, lead to mild to moderate upper respiratory tract infections such as colds and pneumonia, whereas human infections with zoonotic CoVs, such as severe acute respiratory syndrome (SARS) in 2003 and Middle East respiratory syndrome (MERS) in 2012, caused severe respiratory diseases with high morbidity and mortality, posing a significant threat to public health across the world. The outbreak of coronavirus disease 2019 (COVID-19) is an ongoing pandemic that is caused by severe acute respiratory syndrome coronavirus 2 (SARS-CoV-2), a new human coronavirus that appears to be more readily transmitted from human to human $[3,4]$. It is $96 \%$ identical at the whole-genome level to a bat coronavirus and shares $79.6 \%$ sequence identity to SARS-CoV [5]. The ongoing SARS-CoV-2 pandemic has caused over 13 million infections and over 560,000 deaths worldwide, and the numbers are still increasing [6]. It marks the third introduction of a highly pathogenic $\mathrm{CoV}$ into the human population in the twentyfirst century. Currently, no efficacious antiviral drugs and vaccines have been approved for the prophylaxis or treatment of the highly virulent SARS-CoV, MERS-CoV, or SARS-CoV-2 infections in humans.

CoVs share key genomic elements that provide promising therapeutic targets [1, 7]. A chymotrypsin-like cysteine protease called 3C-like protease (3CLpro), together with a papain-like protease (PLpro), is required to process polyproteins into mature nonstructural proteins such as RNA-dependent RNA polymerase (RdRp) and helicase, which are essential for viral transcription and

\footnotetext{
${ }^{1}$ CAS Key Laboratory of Receptor Research, Shanghai Institute of Materia Medica, Chinese Academy of Sciences, Shanghai 201203 , China; ${ }^{2}$ University of Chinese Academy of Sciences, Beijing 100049, China; ${ }^{3}$ State Key Laboratory of Drug Research, Shanghai Institute of Materia Medica, Chinese Academy of Sciences, Shanghai 201203 , China; ${ }^{4}$ Jiangsu Key Laboratory of Drug Discovery for Metabolic Disease and State Key Laboratory of Natural Medicines, China Pharmaceutical University, Nanjing 210009 , China; ${ }^{5}$ Shanghai Synchrotron Radiation Facility, Shanghai Advanced Research Institute, Chinese Academy of Sciences, Shanghai 201210, China; ${ }^{6}$ State Key Laboratory of Virology, Wuhan Institute of Virology, Center for Biosafety Mega-Science, Chinese Academy of Sciences, Wuhan 430071, China; ${ }^{7}$ Division of Cardiology and Department of Internal Medicine, Tongji

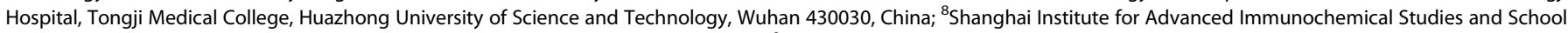
of Life Science and Technology, ShanghaiTech University, Shanghai 201210, China and ${ }^{9}$ School of Life Science and Technology, ShanghaiTech University, Shanghai 201210, China Correspondence: Fang Bai (baifang@shanghaitech.edu.cn) or Yan Wu (wuyan@wh.iov.cn) or Yang Ye (yye@simm.ac.cn) or Ye-chun Xu (ycxu@simm.ac.cn)

These authors contributed equally: Hai-xia Su, Sheng Yao, Wen-feng Zhao, Min-jun Li, Jia Liu, Wei-juan Shang
}

Received: 9 June 2020 Accepted: 14 July 2020

Published online: 31 July 2020 
replication. These polyproteins contains 3 and 11 cleavage sites for PLpro and 3CLpro, respectively, so 3CLpro is also referred to as the main protease. Moreover, the substrate specificity of 3CLpro is highly conserved among different CoVs and is similar to that of the main picornavirus $3 \mathrm{C}$ protease, making it an ideal target for the development of broad-spectrum antiviral drugs [7, 8]. Although several types of substrate-like peptidomimetic inhibitors of SARSCoV 3CLpro, MERS-CoV 3CLpro, or SARS-CoV-2 3CLpro with a covalent mode of action have been reported, none has yet moved into clinical trials yet $[1,7,9,10]$. Classical small molecules with more drug-like properties and binding modes with 3CLpros that are validated by complex structure determination have not yet emerged.

Traditional Chinese medicines (TCMs) have evolved over thousands of years and are invaluable sources for drug discovery and development. As a notable example, the discovery of artemisinin (Qinghaosu), which was originally isolated from the TCM Artemisia annua L. (Qinghao), was a milestone in the treatment of malaria. Shuanghuanglian preparation, a Chinese traditional patent medicine (also called proprietary Chinese medicine) used for the treatment of acute respiratory tract infections since 1973, is a classical purified herbal preparation extracted from three Chinese herbal medicines, namely, Lonicera japonica Thunb., Scutellaria baicalensis Georgi, and Forsythia suspense (Thunb.) Vahl [11]. A variety of formulations of Shuanghuanglian have been developed, including oral liquid (over the counter (OTC) in China), capsule, powder injection, and spray, and adverse drug reactions such as hypersensitivity reactions were reported with the powder injection [12, 13]. According to the theory of TCM, Shuanghuanglian preparations have the efficacy of cold-pungent diaphoresis and clearing away heat and toxic material [14, 15]. Multiple pharmacological activities of Shuanghuanglian, including antibacterial, anti-inflammatory, antiviral, and immune enhancement have been reported [12]. In particular, Shuanghuanglian formulations, its three source herbs and several compounds isolated from these herbs have shown antiviral activities against HIV, adenovirus, influenza virus, and EV71, but the mechanisms of action of these substances remain largely unknown [16-20].

In the present study, we first performed enzymatic assays to rapidly test whether Shuanghuanglian preparations inhibit the proteolytic activities of SARS-CoV-2 3CLpro and PLpro. As Shuanghuanglian preparations showed significant inhibitory activities against 3CLpro, three index components mentioned in the Chinese Pharmacopoeia (chlorogenic acid, phillyrin, and baicalin) together with 25 other compounds in Shuanghuanglian preparations were further investigated. Nine compounds were identified as lower-micromolar-range inhibitors of 3CLpro. Among these, the binding of baicalin as well as baicalein with 3CLpro was comprehensively characterized, and a crystal structure of SARSCoV-2 3CLpro in complex with baicalein, the first noncovalent, nonpeptidomimetic small-molecule inhibitor, was also determined. Finally, the antiviral activities of Shuanghuanglian oral liquids and compounds in a cell-based system were examined. In summary, this study comprehensively explored the in vitro antiviral activities of the Shuanghuanglian preparation and its components at the molecular and cellular levels by using a number of phytochemical, biochemical, biophysical, and pharmacological methods.

\section{MATERIALS AND METHODS}

General chemistry

Shuanghuanglian oral liquids (Sanjing: 18051923; Tailong: 190808012; Xiren: 20190923) were purchased from Yifeng Pharmacy (Shanghai, China). Shuanghuanglian lyophilized powder (1910407) was provided by Harbin Pharmaceutical Group No.2 Traditional Chinese Medicine Factory (Harbin, China). Compounds were from an in-house natural product library. All compounds were analyzed by HPLC-MS (Waters 2695 instrument with a 2998 PDA detector coupled with a Waters Acquity ELSD and a Waters 3100 SQDMS detector using a Waters Sunfire RP-C18 column $(4.6 \times 150 \mathrm{~mm}, 5 \mu \mathrm{m})$ with a $1.0 \mathrm{~mL} / \mathrm{min}$ flow rate). The identification of the constituents in Shuanghuanglian oral liquids was performed on a Waters i-Class UPLC-SYNAPT G2-Si HDMS according to the methods from literatures [21, 22].

Quantitative analysis of chlorogenic acid, phillyrin, baicalin, and baicalein in Shuanghuanglian preparations

Quantitative analysis of chlorogenic acid, phillyrin, baicalin, and baicalein in four Shuanghuanglian preparations was performed on a Waters Acquity UPLC-Acquity PAD. Components were separated on a Waters BEH RP-C18 column $(2.1 \times 100 \mathrm{~mm}, 1.7 \mu \mathrm{m})$ at $30^{\circ} \mathrm{C}$ with a flow rate of $0.4 \mathrm{~mL} / \mathrm{min}$ and an injection volume of $2.0 \mu \mathrm{L}$. Mobile phase $A$ was water with $0.1 \%$ formic acid, and mobile phase B was acetonitrile with $0.1 \%$ formic acid. A nonlinear gradient elution was used (see Supplementary Information). The detection wavelength for these four compounds was set at 277.4 $\mathrm{nm}$. The linear ranges of chlorogenic acid, phillyrin, baicalin, and baicalein were $4.0-150.0,4.0-150.0,5.0-250.0$, and $3-120 \mu \mathrm{g} / \mathrm{mL}$ $\left(R^{2}=0.9999\right)$, respectively. For each sample, at least three independent experiments were performed for the quantitative analysis of the four compounds.

Protein expression and purification

The cDNA of full-length SARS-CoV-2 3CLpro (GenBank: MN908947.3) or SARS-CoV 3CLpro (GenBank: AAP13442.1) was cloned into the PGEX6p-1 vector. To obtain SARS-CoV-2 3CLpro or SARS-CoV 3CLpro with authentic $\mathrm{N}$ and $\mathrm{C}$ terminals, four amino acids (AVLQ) were inserted between the GST tag and the full-length SARS-CoV-2 3CLpro or SARS-CoV 3CLpro, while eight amino acids (GPHHHHHH) were added to the C-terminus of SARS-CoV-2 3CLpro. The plasmid was then transformed into BL21 (DE3) cells for protein expression. The N-terminal GST tag and four amino acids (AVLQ) were self-cleavable. The expressed protein with an authentic Nterminus was purified by a Ni-NTA column (GE Healthcare) and transformed into the cleavage buffer $(150 \mathrm{mM} \mathrm{NaCl}, 25 \mathrm{mM}$ Tris, $\mathrm{pH}$ 7.5) containing human rhinovirus $3 C$ protease to remove the additional residues. The resulting protein sample was further passed through size-exclusion chromatography (Superdex200, GE Healthcare). The eluted protein samples were stored in a solution (10 mM Tris, pH 7.5) for the enzymatic inhibition assay, native-state mass spectrometry and protein crystallization.

To obtain SARS-CoV-2 3CLpro with the GST tag, the CDNA of fulllength SARS-CoV-2 3CLpro was inserted after the PreScission protease digestion site of the PGEX6p-1 vector. The plasmid was transformed into BL21 (DE3) cells for protein expression. The expressed protein was purified by a GST column (GE Healthcare) followed by size-exclusion chromatography (Superdex200, GE Healthcare). The resulting protein was stored in a solution $(25 \mathrm{mM}$ Tris, $\mathrm{pH}$ 7.3) for isothermal titration calorimetry measurements.

The cDNA of full-length SARS-CoV-2 PLpro (GenBank: MN908947.3) was cloned into the $\mathrm{pET}-22 \mathrm{~b}$ vector. A cleavage site for the PreScission protease (LEVLFQGP) and 6His-tag were added to the C-terminus. The plasmid was then transformed into BL21 (DE3) cells for protein expression. The expressed protein was purified by a Ni-NTA column (GE Healthcare) and cleaved by the PreScission protease to remove the His-tag. The resulting protein sample was further passed through size-exclusion chromatography (Superdex200, GE Healthcare). The eluted protein samples were stored in a solution $(50 \mathrm{mM}$ Tris $\mathrm{pH} 7.5,100 \mathrm{mM} \mathrm{NaCl}, 10 \mathrm{mM}$ DTT) for the enzymatic inhibition assay.

The inhibition assay of proteases

A fluorescence resonance energy transfer (FRET) protease assay was applied to measure the inhibitory activity of compounds 
against SARS-CoV-2 3CLpro and SARS-CoV 3CLpro. The fluorogenic substrate MCA-AVLQSGFR-Lys(Dnp)-Lys-NH2 was synthesized by GenScript (Nanjing, China). The FRET-based protease assay was performed as follows. The recombinant SARS-CoV-2 3CLpro (30 $\mathrm{nM}$ final concentration) or SARS-CoV 3CLpro (100 nM final concentration) was mixed with serial dilutions of each compound, oral liquid or the dissolved lyophilized powder in $80 \mu \mathrm{L}$ assay buffer (50 mM Tris-HCl, pH 7.3, 1 mM EDTA) and incubated for 10 min. The reaction was initiated by adding $40 \mu \mathrm{L}$ fluorogenic substrate at a final concentration of $20 \mu \mathrm{M}$. After that, the fluorescence signal at $320 \mathrm{~nm}$ (excitation)/405 nm (emission) measured immediately every $35 \mathrm{~s}$ for $3.5 \mathrm{~min}$ with a Bio-Tek Synergy4 plate reader. The initial velocities of reactions with compounds added at various concentrations compared to the reaction added with DMSO were calculated and used to generate inhibition profiles.

The inhibition of SARS-CoV-2 PLpro by compounds as well as Shuanghuanglian preparations was measured similar to that described previously [23] with a fluorogenic peptide (RLRGGAMC) synthesized by GenScript (Nanjing, China). The reactions were performed in a total volume of $120 \mu \mathrm{L}$. First, $50 \mathrm{nM}$ PLpro was incubated with the indicated concentrations of tested compounds or Shuanghuanglian preparations in the condition of $50 \mathrm{mM}$ HEPES, $\mathrm{pH} 7.5,0.1 \mathrm{mg} / \mathrm{mL}$ BSA, $5 \mathrm{mM}$ DTT for $10 \mathrm{~min}$. The reactions were initiated by the addition of $10 \mu \mathrm{M}$ fluorogenic peptide. After that, the fluorescence signal at $360 \mathrm{~nm}$ (excitation)/460 nm (emission) was measured immediately every $1 \mathrm{~min}$ for $5 \mathrm{~min}$ with a Bio-Tek Synergy4 plate reader. The initial velocities of reactions with compounds or Shuanghuanglian added at various concentrations compared to the reaction added with DMSO were calculated and used to generate inhibition profiles.

For each compound or Shuanghuanglian preparation, at least three independent experiments were performed for the determination of $I C_{50}$ values. The $I C_{50}$ values were expressed as the mean $\pm \mathrm{SD}$ and determined via nonlinear regression analysis using GraphPad Prism software 8.0 (GraphPad Software, Inc., San Diego, (A, USA).

Isothermal titration calorimetry (ITC) measurements

All measurements were performed by an iTC200 calorimeter (General Electric Co.) in ITC buffer ( $25 \mathrm{mM}$ Tris, pH 7.3) while stirring at $800 \mathrm{rpm}$. The stock solution of compounds and the SARS-CoV-2 3CLpro protein with a GST tag were diluted with the ITC buffer to a compound concentration of $50-100 \mu \mathrm{M}$ and a protein concentration of $0.6-1.5 \mathrm{mM}$ before titrations. The final concentration of DMSO in the reaction buffer was less than $2 \%$ by volume. Compounds were titrated by the protein solution. All titrations were performed using an initial injection of $0.4 \mu \mathrm{L}$ followed by 19 identical injections of $2 \mu \mathrm{L}$ with a duration of $4 \mathrm{~s}$ per injection and a spacing of $120 \mathrm{~s}$ between injections. The last five data points were averaged and subtracted from each titration to account for the heat of dilution. Additional background experiments where the protein solution was titrated into the buffer without the compound revealed no significant shift in the baseline during the course of the measurements. Each measurement was repeated three times.

\section{Native-state mass spectrometry studies}

All mass spectrometry (MS) measurements were performed with a scimaX magnetic resonance mass spectrometry (MRMS) system (Bruker Daltonik $\mathrm{GmbH}$, Bremen, Germany). The sample solutions were infused into the system with a syringe $(50 \mu \mathrm{L})$ at a flow rate of $120 \mu \mathrm{L} / \mathrm{h}$ using electrospray ionization in a positive ion mode. Data were acquired in the mass-to-charge $(\mathrm{m} / \mathrm{z})$ range of $400-6000$ with a transient length of $3.92 \mathrm{~s}$ in quadrupolar detection, resulting in a resolving power of $54.0 \mathrm{ppb}$ at $\mathrm{m} / \mathrm{z}$ 3240. The source and ion transfer parameters were optimized as follows: skimmer $1100 \mathrm{~V}$, funnel $1180 \mathrm{~V}$, funnel RF amplitude 200
$\mathrm{V}$, collision cell frequency $2.0 \mathrm{MHz}$, ion transfer frequency $2 \mathrm{MHz}$, time of flight to analyzer cell $2.0 \mathrm{~ms}$ with the RF amplitude of 350 $\mathrm{V}$, and source temperature $200^{\circ} \mathrm{C}$. To optimize protein performance, the mass range around the charge state $18^{+}$was isolated with the quadrupole using a quadrupole mass window of $200 \mathrm{Da}$ with a center mass of the quadrupole of $\mathrm{m} / \mathrm{z} 3750$; the magnitude was set to $4 \mathrm{M} ; 200$ single scans were added. For ligand-binding screening and dissociation constant $\left(K_{\mathrm{d}}\right)$ determination, the magnitude was set to $128 \mathrm{~K}$, and 1000 single scans were added.

The protein sample of SARS-CoV-2 3CLpro was bufferexchanged with $10 \mathrm{mM}$ ammonium acetate buffer $(\mathrm{pH} 6.8)$. For optimization of the MS conditions, the protein was diluted to 2 $\mu \mathrm{M}$. For ligand-binding screening studies and $K_{\mathrm{d}}$ determination, samples were prepared with the protein at $1 \mu \mathrm{M}$ and the ligand at a series of concentrations $(50,25,12.5,6.25,3.13,1.56,0.78 \mu \mathrm{M}$ for baicalin and $10,5,2.5,1.25,0.63,0.31,0.16,0.08 \mu \mathrm{M}$ for baicalein). The incubation time was $1 \mathrm{~h}$ at $37^{\circ} \mathrm{C}$. Three independent experiments were performed for the determination of the $K_{\mathrm{d}}$.

Mass spectra were deconvoluted with SNAP2 in DataAnalysis 5.2 (Bruker Daltonics, Bremen, Germany). Charge states $18^{+}$and $19^{+}$were used to calculate the free protein and protein-ligand complex intensities. The relative abundances of the protein-ligand complex to total protein in the mass spectra were calculated as reported previously [24].

Protein crystallization and structure determination The purified SARS-CoV-2 3CLpro protein was concentrated to 7 $\mathrm{mg} / \mathrm{mL}$ for crystallization. The protein was incubated $1 \mathrm{~h}$ with 10 $\mathrm{mM}$ baicalein before crystallization condition screening. Crystals of the complex were obtained at $20^{\circ} \mathrm{C}$ by mixing equal volumes of protein-baicalein and a reservoir (16\% PEG6000, $100 \mathrm{mM}$ MES, pH 5.8 , 3\% DMSO) with a hanging-drop vapor diffusion method. Crystals were flash-frozen in liquid nitrogen in the presence of the reservoir solution supplemented with $20 \%$ glycerol. X-ray diffraction data were collected at beamline BL18U1 at the Shanghai Synchrotron Radiation Facility [25]. The data were processed with HKL3000 software packages [26]. The complex structure was solved by molecular replacement using the program PHASER [27] with a search model of PDB code 6LU7. The model was built using Coot [28] and refined with a simulated annealing protocol implemented in the program PHENIX [29]. The refined structure was deposited to the Protein Data Bank with the accession code listed in Supplementary Table S1. The complete statistics as well as the quality of the solved structure are also shown in Supplementary Table S1.

The cell-based antiviral activity assay

The Vero E6 cell line was obtained from American Type Culture Collection (ATCC, Manassas, USA) and maintained in minimum Eagle's medium (MEM; Gibco Invitrogen) supplemented with $10 \%$ fetal bovine serum (FBS; Invitrogen, UK) in a humid incubator with $5 \% \mathrm{CO}_{2}$ at $37^{\circ} \mathrm{C}$. The cytotoxicity of the three Shuanghuanglian oral liquids and the tested compounds to the Vero E6 cells was determined by CCK8 assays (Beyotime, China). A clinical isolate SARS-CoV-2 [5] was propagated in Vero E6 cells, and the viral titer was determined as described previously [30]. All infection experiments were performed at biosafety level-3 (BSL-3).

Preseeded Vero E6 cells $\left(5 \times 10^{4}\right.$ cells/well) were incubated with different concentrations of oral liquids or compounds for $1 \mathrm{~h}$, and the virus was subsequently added (a multiplicity of infection of 0.01 ) to infect the cells for $2 \mathrm{~h}$. After that, the virus-compound mixture was removed, and the cells were further cultured with a fresh compound-containing medium. At $48 \mathrm{~h}$ post infection, the cell supernatant was collected, and the viral RNA in the supernatant was submitted to quantitative real-time RT-PCR (qRT-PCR) analysis as described previously [30]. DMSO was used in the controls. At least three independent experiments were carried out for each oral liquid, baicalin and baicalein. The half- 
maximal effective concentration $\left(E_{50}\right)$ values are expressed as the mean \pm SD from independent experiments and were determined via nonlinear regression analysis using GraphPad Prism software 8.0 (GraphPad Software, Inc., San Diego, CA, USA).

\section{RESULTS}

Inhibition of SARS-CoV-2 3CLpro and PLpro by Shuanghuanglian preparations

The pivotal role of the $3 C L$ protease (3CLpro) in processing polyproteins into individual functional proteins for viral replication and the highly conserved substrate specificity of the enzyme among CoVs make it a promising target for screening inhibitors. A FRET protease assay was applied to measure the proteolytic activity of the recombinant SARS-CoV-2 3CLpro on a fluorogenic substrate. The details of the assay are described above. This FRETbased protease assay was utilized to measure the inhibitory activities of Shuanghuanglian preparations as well as compounds against SARS-CoV-2 3CLpro. To quickly find out whether Shuanghuanglian preparations and their components have inhibitory activities against the proteases, we added the diluted Shuanghuanglian oral liquid directly into the enzymatic reaction without visible precipitation or aggregation. To our surprise, the oral liquid showed dose-dependent inhibition of SARS-CoV-2 $3 C L$ pro, and the resulting $\mathrm{IC}_{50}$ values were $0.090,0.064$, and 0.076 $\mu \mathrm{L} / \mathrm{mL}$ for three Shuanghuanglian oral liquids produced by three different pharmaceutical companies (Table 1 and Fig. 1a-c). Moreover, we dissolved the lyophilized powder of Shuanghuanglian for injection in phosphate-buffered saline to prepare a stock solution at a concentration of $750 \mathrm{mg} / \mathrm{mL}$. The subsequently determined $\mathrm{IC}_{50}$ of the lyophilized powder was $0.010 \mathrm{mg} / \mathrm{mL}$ (Fig. 1d). Taken together, these data demonstrate that the Shuanghuanglian preparations show inhibitory activity against SARS-CoV-2 3CLpro, and $0.009 \%, 0.0064 \%$, and $0.0076 \%$ of the respective oral liquids in the enzymatic reaction system resulted in $50 \%$ inhibition of the enzyme's proteolytic activity.
Subsequently, a fluorogenic peptide (RLRGG-AMC) was used to determine the inhibitory activities of four Shuanghuanglian preparations against SARS-CoV-2 PLpro which is also a crucial protease in processing polyproteins into individual functional proteins for viral replication. All three oral liquids as well as the lyophilized powder of Shuanghuanglian again exhibited dosedependent inhibition of SARS-CoV-2 PLpro, but with the much higher $\mathrm{IC}_{50}$ values of $3.65 \mu \mathrm{L} / \mathrm{mL}, 4.44 \mu \mathrm{L} / \mathrm{mL}, 4.19 \mu \mathrm{L} / \mathrm{mL}$, and 0.14 $\mathrm{mg} / \mathrm{mL}$, respectively, compared with their $\mathrm{IC}_{50}$ values toward 3CLpro (Supplementary Fig. S1). These findings suggested that Shuanghuanglian preparations could inhibit the hydrolytic activity of both SARS-CoV-2 3CLpro and PLpro, and their potency toward 3 CLpro is much more significant than toward PLpro.

Inhibition of SARS-CoV-2 3CLpro by baicalin and baicalein According to the Chinese Pharmacopoeia (2015), chlorogenic acid from L. japonica Thunb., phillyrin from $F$. suspense (Thunb.) Vahl., and baicalin from S. baicalensis Georgi (Supplementary Fig. S2), are the index components of Shuanghuanglian oral liquids, with concentrations of over $0.6,0.3$, and $10 \mathrm{mg} / \mathrm{mL}$, respectively. These three compounds were thus individually tested by the FRET-based protease assay. Baicalin and chlorogenic acid showed an $\mathrm{IC}_{50}$ of 6.41 and $39.48 \mu \mathrm{M}$ against 3CLpro, respectively, while phillyrin hardly had inhibitory activity at a concentration of $10 \mu \mathrm{M}$ (Table 1). Furthermore, the contents of chlorogenic acid, phillyrin, and baicalin in the four tested Shuanghuanglian samples were determined by the ultra-high-performance liquid chromatography (UPLC) (Supplementary Fig. S3), and the results are shown in Table 1. Baicalin concentrations of $12.72 \mathrm{mg} / \mathrm{mL}, 12.78 \mathrm{mg} / \mathrm{mL}$, $17.52 \mathrm{mg} / \mathrm{mL}$, and $274.08 \mathrm{mg} / \mathrm{g}$ were included in the three oral liquids and the lyophilized powder, respectively. Taking these data and the $\mathrm{IC}_{50}$ values of the four Shuanghuanglian samples into account, the calculated concentrations of baicalin in the reaction system when the four Shuanghuanglian samples reached $50 \%$ inhibition of the enzyme's activity ranged from 1.83 to $6.14 \mu \mathrm{M}$, which were closed to the $I C_{50}$ of pure baicalin $(6.41 \mu \mathrm{M})$. These

Table 1. Inhibition of SARS-CoV-2 3CLpro by Shuanghuanglian preparations as well as their ingredients, and the determined content of chlorogenic acid, phillyrin, baicalin, and baicalein in Shuanghuanglian preparations.

\begin{tabular}{llcccc}
\hline Entities & $\mathrm{IC}_{50}$ & Chlorogenic acid & Phillyrin & Baicalin & \multicolumn{1}{c}{ Baicalein } \\
\hline Oral liquid 1 & $0.090 \pm 0.004 \mu \mathrm{L} / \mathrm{mL}$ & $0.72 \pm 0.01 \mathrm{mg} / \mathrm{mL}$ & $0.29 \pm 0.01 \mathrm{mg} / \mathrm{mL}$ & $12.72 \pm 0.30 \mathrm{mg} / \mathrm{mL}$ & $0.12 \pm 0.00 \mathrm{mg} / \mathrm{mL}$ \\
Oral liquid 2 & $0.064 \pm 0.011 \mu \mathrm{L} / \mathrm{mL}$ & $0.78 \pm 0.01 \mathrm{mg} / \mathrm{mL}$ & $0.32 \pm 0.01 \mathrm{mg} / \mathrm{mL}$ & $12.78 \pm 0.18 \mathrm{mg} / \mathrm{mL}$ & $0.06 \pm 0.00 \mathrm{mg} / \mathrm{mL}$ \\
Oral liquid 3 $^{\mathrm{a}}$ & $0.076 \pm 0.007 \mu \mathrm{L} / \mathrm{mL}$ & $0.78 \pm 0.01 \mathrm{mg} / \mathrm{mL}$ & $0.28 \pm 0.01 \mathrm{mg} / \mathrm{mL}$ & $17.52 \pm 0.17 \mathrm{mg} / \mathrm{mL}$ & $0.22 \pm 0.00 \mathrm{mg} / \mathrm{mL}$ \\
Lyophilized powder $^{\mathrm{a}}$ & $0.010 \pm 0.001 \mathrm{mg} / \mathrm{mL}$ & $19.36 \pm 0.35 \mathrm{mg} / \mathrm{g}$ & $2.92 \pm 0.05 \mathrm{mg} / \mathrm{g}$ & $274.08 \pm 2.82 \mathrm{mg} / \mathrm{g}$ & $1.87 \pm 0.04 \mathrm{mg} / \mathrm{g}$ \\
Chlorogenic acid $^{\mathrm{a}}$ & $39.48 \pm 5.51 \mu \mathrm{M}$ & & & \\
Phillyrin & $7.8 \%$ inhibition @ $10 \mu \mathrm{M}$ & & & \\
Baicalin & $6.41 \pm 0.95 \mu \mathrm{M}$ & & & \\
Baicalein & $0.94 \pm 0.20 \mu \mathrm{M}$ & & & \\
\hline
\end{tabular}

aShuanghuanglian oral liquids and the lyophilized powder for injection were produced by three different pharmaceutical companies.

a

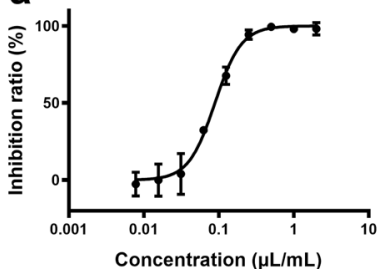

b

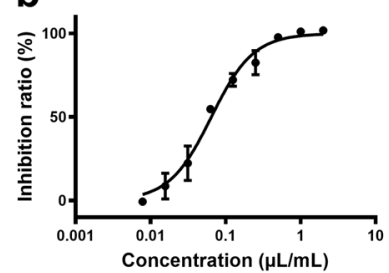

C

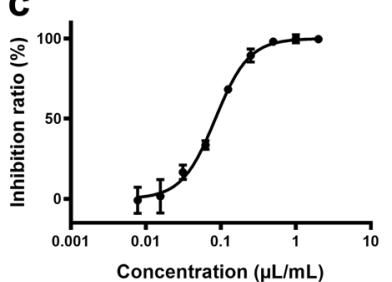

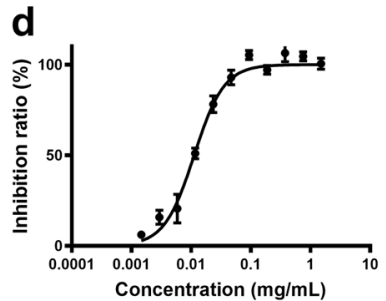

Fig. 1 Inhibition of SARS-CoV-2 3CLpro by Shuanghuanglian. a Representative inhibition curves for oral liquid 1, b oral liquid 2, c oral liquid 3 , and $\mathbf{d}$ the lyophilized powder for injection of Shuanghuanglian against SARS-CoV-2 3CLpro. All data are shown as mean \pm SD. 
data suggest that the inhibition of SARS-CoV-2 3CLpro by Shuanghuanglian preparations is mainly due to their abundant component, baicalin, although other ingredients may also possess inhibitory activities against the protease. Furthermore, we determined the inhibition of 3CLpro by baicalein, an aglycone of baicalin, and the resulting $\mathrm{IC}_{50}$ was $0.94 \mu \mathrm{M}$ (Table 1 and Supplementary Fig. S2). There was a small amount of baicalein in Shuanghuanglian preparations (Table 1). Thus, baicalin and baicalein are two novel nonpeptidomimetic inhibitors of SARSCoV-2 3CLpro with single-digit micromolar potency. In contrast, the inhibition of SARS-CoV-2 PLpro by these two compounds at a concentration of $50 \mu \mathrm{M}$ is $<50 \%$.
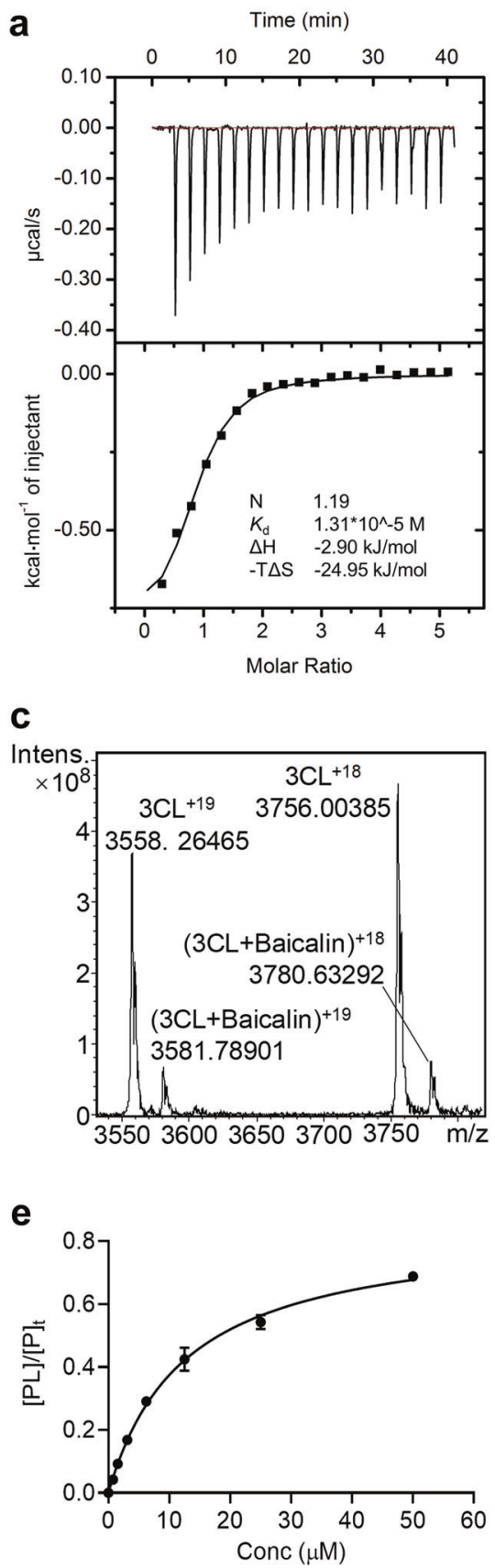

Protein-ligand binding supported by ITC and ESI-MS

To validate the binding of baicalin and baicalein with SARS-CoV-2 3 CLpro and exclude the possibility of the pan-assay interference compounds [31], their binding affinities with the protease were measured by ITC, widely known as an invaluable tool used to determine the thermodynamic parameters of protein-ligand interactions, such as the $K_{\mathrm{d}}$ (Fig. $2 \mathrm{a}, \mathrm{b}$ and Table 2). The resulting $K_{\mathrm{d}}$ of baicalin and baicalein binding with SARS-CoV-2 3CLpro was 11.50 and $4.03 \mu \mathrm{M}$, respectively. These had good correlations with the $\mathrm{IC}_{50}$ values mentioned above, demonstrating that specific binding of the compounds with the enzyme is responsible for their bioactivities. Baicalein showed a high binding efficiency to

b

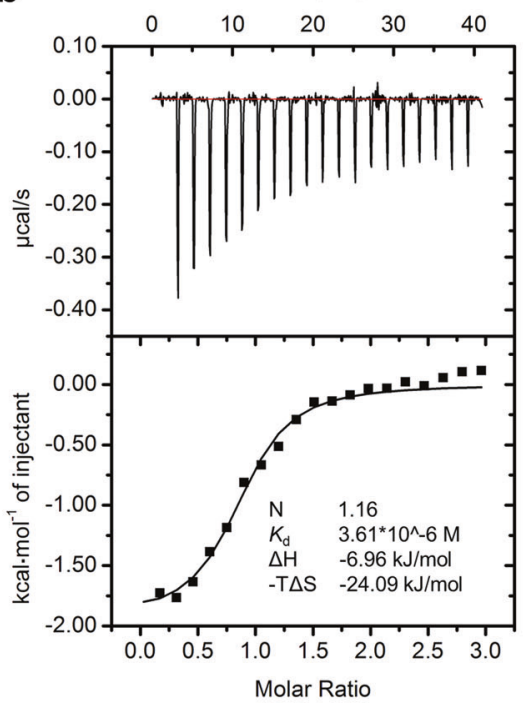

d

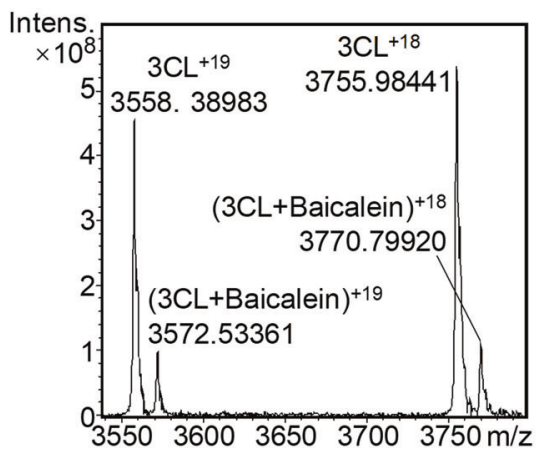

f

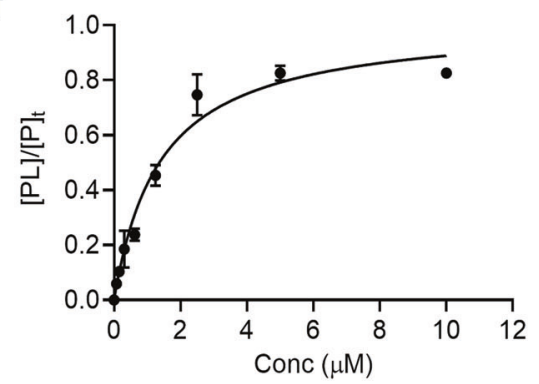

Fig. 2 Binding of baicalin and baicalein with SARS-CoV-2 3CLpro characterized by ITC and ESI-MS. a Representative thermodynamic profiles of baicalin and (b) baicalein binding with SARS-CoV-2 3CLpro in solution, resulting from ITC measurements. c Native-state electrospray ionization mass spectrometry spectra of SARS-CoV-2 3CLpro with baicalin and (d) baicalein. e Binding affinities of baicalin and (f) baicalein with SARS-CoV-2 3CLpro determined by native-state mass spectrometry. Fraction of ligand bound protein ([PL]/[P $\left.]_{t}\right)$ obtained under optimized conditions plotted against total ligand concentrations. All data are shown as mean \pm SD. 
Table 2. Binding affinities of baicalin and baicalein with SARS-CoV-2 3CLpro determined by ITC and MRMS, and the calculated ligand efficiency (LE) of two compounds.

\begin{tabular}{|c|c|c|c|c|c|}
\hline Compounds & $K_{\mathrm{d}}{ }^{\mathrm{ITC}}(\mu \mathrm{M})$ & $\Delta G^{\mathrm{ITC}}(\mathrm{kJ} / \mathrm{mol})$ & $\mathrm{LE}^{\mathrm{ITC}}(\mathrm{kcal} / \mathrm{mol})$ & $K_{\mathrm{d}}{ }^{\mathrm{MRMS}}(\mu \mathrm{M})$ & $I C_{50}(\mu M)$ \\
\hline Baicalin & $11.50 \pm 1.89$ & $-28.20 \pm 0.42$ & 0.21 & $12.73 \pm 0.81$ & $6.41 \pm 0.95$ \\
\hline Baicalein & $4.03 \pm 0.37$ & $-30.78 \pm 0.24$ & 0.37 & $1.40 \pm 0.10$ & $0.94 \pm 0.20$ \\
\hline
\end{tabular}

SARS-CoV-2 3CLpro, with a calculated ligand efficiency of 0.37 $\mathrm{kcal} / \mathrm{mol}$. Moreover, the ITC profiles in combination with their chemical structures suggest that baicalin and baicalein act as noncovalent inhibitors of SARS-CoV-2 3CLpro.

Native-state electrospray ionization mass spectrometry (ESI-MS) has been used extensively to directly observe native-state proteins and protein complexes, allowing the direct detection of protein-ligand noncovalent complexes with $K_{\mathrm{d}}$ values as weak as $1 \mathrm{mM}$ [32]. A $\Delta m / z$ between the [protein + ligand] $m / z$ and the [unbound protein] $\mathrm{m} / \mathrm{z}$ identifies a ligand as a binder with the correct molecular weight, while the ratio of the intensity of the [protein + ligand] peaks relative to the [unbound protein] peaks provides a qualitative indication of the ligand-binding affinity. Herein, ESI-MS analysis using high-resolution MRMS was carried out to detect the binding of baicalin and baicalein with SARS-CoV23 CLpro. To optimize the free protease performance, the mass range around charge state $18^{+}$was isolated with a center mass of the quadrupole of $\mathrm{m} / \mathrm{z} 3750$ (Supplementary Fig. S4). For the ligand-binding screening studies, two charge states $\left(18^{+}\right.$and $\left.19^{+}\right)$ were used to calculate the free protein and protein-ligand complex intensities. The representative spectra of samples containing SARS-CoV-2 3CLpro $(1 \mu \mathrm{M})$ and baicalin $(3.13 \mu \mathrm{M})$, or baicalein $(0.31 \mu \mathrm{M})$ acquired under both optimized and screening conditions are shown in Fig. 2c, d, demonstrating specific binding of baicalin or baicalein with the protease. Moreover, the plot of the fraction of the bound protease versus the total concentration of the compound showed that the $K_{\mathrm{d}}$ values of baicalin and baicalein were 12.73 and $1.40 \mu \mathrm{M}$, respectively (Fig. 2e, f), in keeping with the results from the ITC measurements.

Crystal structure of SARS-CoV-2 3CLpro in complex with baicalein The mode of action of baicalein and the structural determinants associated with its binding with SARS-CoV-2 3CLpro were further explored using X-ray protein crystallography. The crystal structure of SARS-CoV-2 3CLpro in complex with baicalein was determined at a resolution of $2.2 \AA$ (Fig. 3 and Supplementary Table S1). The protease had a catalytic Cys 145-His41 dyad and an extended binding site, features shared by SARS-CoV 3CLpro and MERS-CoV 3CLpro (Fig. 3a). The inhibitor bound in a core region of the substrate-binding site at the surface of the protease between domains I and II (Fig. 3a, b). Examination of the active site of the complex revealed that three phenolic hydroxyl groups of baicalein made multiple hydrogen bonds with the main chains of Leu141/Gly143 as well as the side chains of Ser144/His163 with or without the aid of a buried water molecule (Fig. 3c). The only carbonyl group established a hydrogen bond with the main chain of Glu166, while the free phenyl ring inserted into the S2 subsite by making hydrophobic interactions with multiple residues Gln189/Arg188/Met49/Cys44/His41. Notably, apart from the hydrophobic interactions, the catalytic Cys 145 and His41 also formed S- $\pi$ (at a distance of $3.3 \AA$ from the sulfur to the centroid of the phenyl ring) and $\pi-\pi$ interactions with the aromatic rings of baicalein, respectively. The side chain of Asn142 also established $\mathrm{NH}_{2}-\pi$ interactions (at a distance of $3.6 \AA$ from the nitrogen to the centroid of the phenyl ring) with baicalein, which together with the interactions contributed by Cys145 led the phenyl ring with three $\mathrm{OH}$ groups to be sandwiched between Cys 145 and Asn142. Moreover, Met165 contacted the middle ring
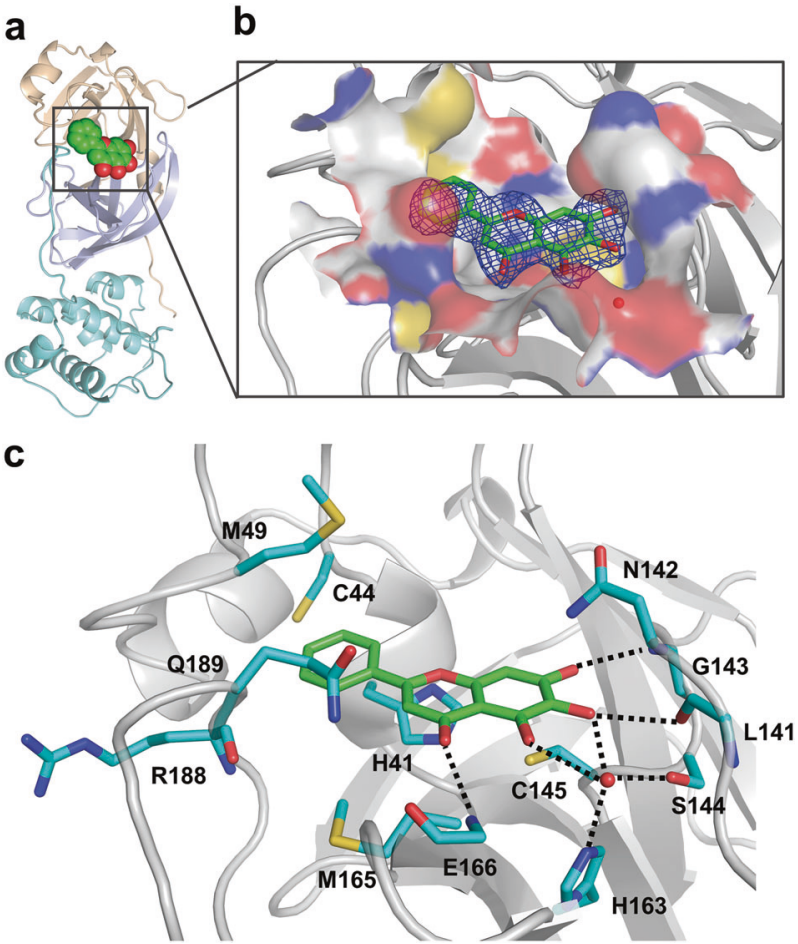

Fig. 3 Crystal structure of SARS-CoV-2 3CLpro in complex with baicalein. a Overview of the structure of baicalein-bound SARS-CoV2 3CLpro (PDB code 6M2N). Protein is shown in cartoon representation and three domains are shown by different colors. Baicalein is shown as spheres with carbons in green. b $2 F o-F c$ density map contoured at $1.0 \sigma$ is shown for baicalein in complex with SARS-CoV-2 3CLpro. The protein is colored gray. The substratebinding pocket is represented by an intermolecular surface. The inhibitor, baicalein, is shown as green sticks and a buried water molecule is displayed as a red ball. c Interactions formed between baicalein (green) and surrounding residues (cyan). Residues as well as the ligand are shown as sticks and hydrogen bonds are represented by black-dashed lines.

of baicalein via hydrophobic interactions. Consequently, baicalein was productively ensconced in the core of the substratebinding pocket and interacted with two catalytic residues, the oxyanion loop (residues 138-145), Glu166, and the S1/ S2 subsites, which are the key elements for the recognition of substrates and peptidomimetic inhibitors [33]. Although baicalein did not move deeply into the S1 subsite, its phenolic hydroxyl groups did form contacts with the crucial residue of this subsite, His163, via the water molecule. With the aid of an array of direct and indirect hydrogen bonds with Leu141/Gly143/ Ser144, baicalein fixed the conformation of the flexible oxyanion loop, which served to stabilize the tetrahedral transition state of the proteolytic reaction. These results together provide the molecular details of baicalein recognition by SARS-CoV-2 3CLpro and an explanation for the observed potent activity of this small molecule against the protease. 

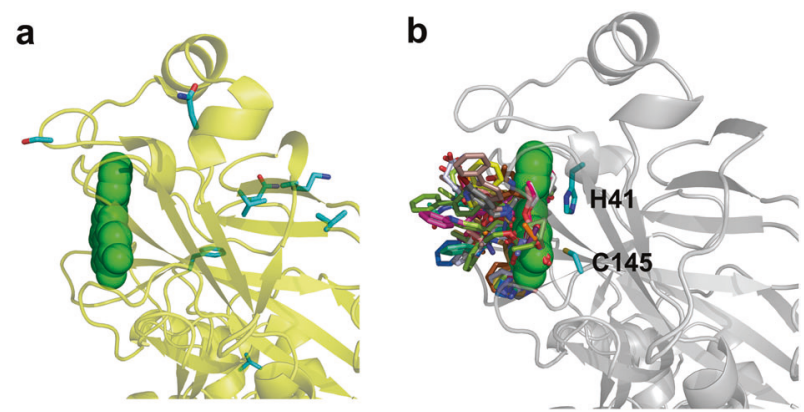

Fig. 4 Unique binding mode of baicalein with 3CLpro. a The structure of SARS-CoV 3CLpro in complex with baicalein was generated by superimposing the structure of SARS-CoV-2 3CLpro/ baicalein (PDB code 6M2N) with that of SARS-CoV 3CLpro/TG0204998 (PDB code 2ZU4). SARS-CoV 3CLpro is shown in yellow cartoon and baicalein is shown as green spheres. Residues differing in two proteases are shown as cyan sticks. b A survey of the binding modes of known inhibitors as well as baicalein with SARS-CoV $3 \mathrm{CLpro}$ are shown by superimposing all the crystal structures of inhibitor-bound SARS-CoV 3CLpro (PDB codes: 2A5I, 2A5K, 2ALV, 2AMD, 2AMQ, 2GTB, 2GX4, 2OP9, 2YNB, 2ZU4, 2ZU5, 3ATW, 3AVZ, $3 A W 0,3 S N 8,3 S N A, 3 S N B, 3 S N C, 3 S N D, 3 S N E, 3 S Z N, 3 V 3 M, 4 M D S$, $4 T W W, 4 T W Y, 4 W Y 3,5 C 5 N$, and 5C5O). Baicalein is shown as green spheres, and other inhibitors and the two catalytic residues are shown as sticks.

Unique binding mode of baicalein with SARS-CoV-2 3CLpro The amino acid sequence of SARS-CoV-2 3CLpro has $96 \%$ sequence identity to SARS-CoV $3 C L$ pro. As a result, the inhibition assay showed that baicalein inhibited SARS-CoV 3CLpro with an $I_{50}$ of $1.18 \pm 0.37 \mu \mathrm{M}$, similar to its $I_{50}$ toward SARS-CoV-2 3 CLpro. Twelve residues differed between the two proteases, and none of them participated in the direct contact with baicalein. The high level of sequence identity between the two proteases allows one to assume that baicalein will bind to SARS-CoV 3CLpro in the same way as it does to SARS-CoV-2 3CLpro. Thus, a threedimensional model of SARS-CoV 3CLpro in complex with baicalein was constructed by superimposing the crystal structure of SARSCoV-2 3CLpro/baicalein with that of SARS-CoV 3CLpro/TG-0204998 (PDB code 2ZU4) (Fig. 4a). Subsequently, all of the crystal structures of the inhibitor-bound SARS-CoV 3CLpro were collected for a comparison analysis (Fig. 4b). This revealed that the binding mode of baicalein with SARS-CoV 3CLpro was distinctively different from those of known inhibitors. Assuming the peptidomimetic inhibitors were delineated as "swords" to resemble the binding of substrates, baicalein worked as a "shield" in front of two catalytic dyads to effectively prevent substrate access to the catalytic dyad within the active site (Fig. 4b). Such a unique binding mode in combination with its high ligand-binding efficiency and small molecular weight makes baicalein a valuable lead for further development.

Inhibition of SARS-CoV-2 3CLpro by other compounds in Shuanghuanglian preparations

Inspired by the good activities of baicalin and baicalein against SARS-CoV-2 3CLpro, we carried out a phytochemical analysis of Shuanghuanglian oral liquids. A total of 28 compounds, including baicalein and baicalin, were rapidly identified from the Shuanghuanglian oral liquid using UPLC-QTOF. The profiles of all 28 compounds in the Shuanghuanglian oral liquid on UPLC are shown in Supplementary Fig. S5. In addition to those of baicalein, baicalin, chlorogenic acid, and phillyrin, the inhibitory activities of the remaining 24 compounds against SARS-CoV-2 3CLpro were determined (Table 3). To our surprise, seven compounds besides baicalein and baicalin showed good inhibition of 3CLpro: Forsythoside B, scutellarein, forsythoside A, forsythoside I, isoforsythiaside, forsythoside $E$, and forsythoside $H$ had $I C_{50}$ values of $2.88,3.02,3.18,5.47,5.85,6.68$, and $10.17 \mu \mathrm{M}$, respectively. Scutellarein is from $\mathrm{S}$. baicalensis, but the other six compounds are ingredients of $F$. suspensa. These results provide a good basis to explain the potent inhibition of SARS-CoV-2 3CLpro by Shuanghuanglian oral liquids, although these compounds have very low concentrations in the oral liquids compared with baicalin. Nevertheless, the inhibition of SARS-CoV-2 PLpro by all 28 compounds is generally weak, which is consistent with the low potency of Shuanghuanglian preparations toward PLpro (Table 3).

Antiviral activities of Shuanghuanglian and its ingredients against SARS-CoV-2 in cells

We further evaluated the antiviral efficacy of Shuanghuanglian preparations and compounds against a clinical isolate of SARSCoV-2 [5] in Vero E6 cells. The cytotoxicity of the three Shuanghuanglian oral liquids in Vero E6 cells was first determined by the CCK8 assay, and the resulting half-cytotoxic concentration $\left(\mathrm{CC}_{50}\right)$ was over $12.5 \mu \mathrm{L} / \mathrm{mL}$ (Fig. $5 \mathrm{a}-\mathrm{C}$ ). Subsequently, the Vero E6 cells were infected with SARS-CoV-2 at a multiplicity of infection of 0.01 in the presence of different concentrations of the oral liquids. The antiviral efficacies were evaluated by quantifying the viral copy numbers in the cell supernatant via qRT-PCR. As shown in Fig. $5 a-c$, the three oral liquids all showed dose-dependent inhibition of SARS-CoV-2 replication, and the resulting halfmaximal effective concentrations $\left(\mathrm{EC}_{50}\right)$ were $1.20,1.07$, and $0.93 \mu \mathrm{L} / \mathrm{mL}$, respectively. Like their $\mathrm{IC}_{50}$ values toward 3CLpro (Table 1), the $\mathrm{EC}_{50}$ values of the three oral liquids were also close to each other.

Analogously, the antiviral activities of the compounds identified in Shuanghuanglian oral liquids were determined. Most of the compounds at a concentration of $30 \mu \mathrm{M}$ showed weak or no antiviral activity (Supplementary Fig. S6). However, both baicalin and baicalein showed dose-dependent inhibition of SARS-CoV-2 replication, and the resulting $\mathrm{EC}_{50}$ values were 27.87 and $2.94 \mu \mathrm{M}$, respectively (Fig. $5 \mathrm{~d}$, e). The resulting $\mathrm{CC}_{50}$ values of baicalin and baicalein in Vero E6 cells were over $200 \mu \mathrm{M}$, demonstrating the very low cytotoxicity of the two compounds (Fig. $5 \mathrm{~d}$, e). The corresponding selectivity index $\left(\mathrm{SI}=\mathrm{CC}_{50} / \mathrm{EC}_{50}\right)$ values were $>7$ and $>68$ for baicalin and baicalein, respectively. Therefore, the cellbased antiviral activity of baicalein was superior to that of most of the reported compounds and was close to those of chloroquine $\left(E C_{50}: 2.71 \mu \mathrm{M} ; \mathrm{SI}=100.81\right)$ and hydroxychloroquine $\left(E C_{50}: 4.51\right.$ $\mu \mathrm{M} ; \mathrm{SI}=55.32$ ) [30]. In addition, wogonin, which is an inhibitor of neither 3CLpro nor PLpro, also showed good activity against the replication of SARS-CoV-2 in Vero E6 cells $\left(\mathrm{EC}_{50}: 6.88 \mu \mathrm{M}\right.$, Supplementary Fig. S7). Taken together, these findings suggest that the good antiviral activities of Shuanghuanglian oral liquids in Vero E6 cells are mainly due to the antiviral activities of baicalin, considering its high concentration in the oral liquid, while baicalein and wogonin, as trace components of the oral liquids, also exhibit the potent antiviral activities.

\section{DISCUSSION}

Emerging CoVs such as SARS-CoV, MERS-CoV, and SARS-CoV-2 cause globally prevalent and severe diseases in humans, and there is still no cure for these diseases. In view of the long history of Shuanghuanglian preparations in treating respiratory tract infections and the urgent need for drugs against COVID-19, we investigated the anti-SARS-CoV-2 potential of Shuanghuanglian preparations in vitro. Both the oral liquids (OTC) and the lyophilized powder for injection of Shuanghuanglian demonstrate dose-dependent inhibition of SARS-CoV-2 3CLpro and PLpro, which are promising therapeutic targets for anti-CoV agents. In particular, the inhibitory activities of Shuanghuanglian preparations against 3 CLpro are significant, as the relevant $I C_{50}$ values of three Shuanghuanglian oral liquids produced by three different pharmaceutical companies are $0.090,0.064$, and $0.076 \mu \mathrm{L} / \mathrm{mL}$, 
Table 3. Inhibition of SARS-CoV-2 3CLpro and PLpro by 28 compounds included in Shuanghuanglian oral liquids.

\begin{tabular}{|c|c|c|c|c|c|c|c|}
\hline & \multirow[t]{3}{*}{ Chemical name } & \multirow[t]{3}{*}{ Plant resource } & \multicolumn{3}{|c|}{ 3CLpro } & \multirow{2}{*}{\multicolumn{2}{|c|}{$\frac{\text { PLpro }}{\text { Inhibition }(\%)(\mu \mathrm{M})}$}} \\
\hline & & & \multicolumn{2}{|c|}{ Inhibition (\%) ( $\mu \mathrm{M})$} & \multirow[t]{2}{*}{$\mathrm{IC}_{50}(\mu \mathrm{M})$} & & \\
\hline & & & 100 & 10 & & 50 & 12.5 \\
\hline 1 & Chlorogenic acid & L. japonica & 76.4 & 20.2 & $39.48 \pm 5.51$ & 12.5 & / \\
\hline 2 & Neochlorogenic acid & & 49.2 & 10.4 & / & 6.2 & / \\
\hline 3 & Cryptochlorogenic acid & & 39.7 & / & / & 14.0 & / \\
\hline 4 & Isochlorogenic acid A & & 77.0 & 18.9 & / & 18.7 & / \\
\hline 5 & Isochlorogenic acid B & & 52.4 & 26.3 & / & 24.2 & / \\
\hline 6 & Isochlorogenic acid C & & 78.2 & 18.4 & / & 11.0 & / \\
\hline 7 & 1,3-Dicaffeoylquinic acid & & 87.3 & 27.8 & / & 14.4 & / \\
\hline 8 & Loganin & & 10.6 & / & / & -1.7 & / \\
\hline 9 & Secoxyloganin & & 4.6 & / & / & -13.0 & / \\
\hline 10 & Luteoloside & & 65.4 & 14.8 & / & 21.5 & l \\
\hline 11 & Baicalin & S. baicalensis & 97.6 & 68.9 & $6.41 \pm 0.95$ & 15.9 & / \\
\hline 12 & Baicalein & & 99.4 & 87.0 & $0.94 \pm 0.20$ & 45.1 & 12.4 \\
\hline 13 & Wogonoside & & 20.4 & / & / & 14.4 & / \\
\hline 14 & Wogonin & & 3.6 & / & / & 52.0 & 35.9 \\
\hline 15 & Scutellarin & & 76.8 & 18.9 & / & 41.8 & 12.7 \\
\hline 16 & Scutellarein & & 101.6 & 90.7 & $3.02 \pm 0.11$ & 65.7 & 14.4 \\
\hline 17 & Oroxylin A-7-O- $\beta-D-$ glucuronide & & 33.0 & / & / & 7.4 & / \\
\hline 18 & Chrysin-7-O- $\beta$-D-glucoronide & & 50.6 & 24.2 & / & 16.3 & / \\
\hline 19 & Phillyrin & F. suspensa & -18.1 & -2.8 & / & -1.2 & / \\
\hline 20 & Phillygenin & & 11.4 & / & / & 8.5 & / \\
\hline 21 & Forsythoside A & & 95.3 & 70.5 & $3.18 \pm 0.12$ & 7.1 & / \\
\hline 22 & Forsythoside B & & 101.4 & 80.9 & $2.88 \pm 0.13$ & 12.7 & / \\
\hline 23 & Forsythoside $\mathrm{E}$ & & 96.6 & 41.9 & $6.68 \pm 0.22$ & -7.0 & / \\
\hline 24 & Forsythoside $\mathrm{H}$ & & 99.3 & 61.7 & $10.17 \pm 0.39$ & 2.5 & / \\
\hline 25 & Forsythoside I & & 95.9 & 46.3 & $5.47 \pm 0.31$ & 1.7 & / \\
\hline 26 & Isoforsythiaside & & 94.4 & 46.8 & $5.85 \pm 0.06$ & 61.4 & 25.1 \\
\hline 27 & Acteoside & & 97.0 & 34.6 & / & 15.6 & / \\
\hline 28 & (+)-Pinoresinol-4-O- $\beta$-D-glucopyraside & & 13.3 & / & / & 8.0 & / \\
\hline
\end{tabular}

respectively, and the $\mathrm{IC}_{50}$ of the lyophilized powder is $0.010 \mathrm{mg} /$ $\mathrm{mL}$. Remarkably, all three oral liquids also show dose-dependent inhibition of SARS-CoV-2 replication in Vero E6 cells, with $\mathrm{EC}_{50}$ values of $1.20,1.07$, and $0.93 \mu \mathrm{L} / \mathrm{mL}$, respectively. Both the $I_{50}$ and $\mathrm{EC}_{50}$ values of the three oral liquids are close to each other, and the $\mathrm{EC}_{50}$ values are approximately tenfold the $\mathrm{IC}_{50}$ values, a common dose response at the molecular and cellular levels. We can thus conjecture that the inhibition of 3CLpro by baicalin, the major ingredient, accounts for most of the anti-SARS-CoV-2 activities of the four Shuanghuanglian samples, although trace components such as baicalein and wogonin also contribute. These results together provide a good basis for further studies of Shuanghuanglian oral liquids for COVID-19 treatment. Encouragingly, the first family case of COVID-19 confirmed in Wuhan and treated with a combination of the Western medicine and Shuanghuanglian oral liquids has been reported, suggesting the promising therapeutic benefit of Shuanghuanglian in COVID-19 treatment [34].

According to the determined concentrations of baicalin in Shuanghuanglian preparations and the $\mathrm{IC}_{50}$ values of the four Shuanghuanglian samples as well as of pure baicalin, baicalin is identified as the major bioactive ingredient in Shuanghuanglian preparations that inhibits SARS-CoV-2 3CLpro. Eight compounds besides baicalin-baicalein, forsythoside A, forsythoside B, forsythoside $E$, forsythoside $H$, forsythoside $I$, isoforsythiaside, and scutellarein-show lower-micromolar activities against $3 C$ pro, although their concentrations in Shuanghuanglian preparations are much lower than those of baicalin. Therefore, these compounds also contribute to the inhibition of SARS-CoV-2 3 CLpro by Shuanghuanglian preparations, although baicalin is the major contributor. Given the high conservation of $3 C L$ pro among various CoVs, Shuanghuanglian preparations as well as the nine compounds are expected to inhibit other 3CLpros of CoVs. However, except baicalein and baicalin, the remaining compounds do not possess good antiviral activity in Vero E6 cells, which might be ascribed to the low permeability of the cell membrane. Wogonin is not a potent inhibitor of 3CLpro or PLpro at the molecular level, but it does exhibit a good antiviral activity in Vero E6 cells, like baicalein and baicalin. The molecular mechanism underlying the antiviral activity of wogonin remains to be determined.

$3 C$ Lpros are cysteine proteases excised from viral polyproteins by their own proteolytic activities and often form homodimers with one active site per subunit. The substrate specificity of $3 C$ pros is characterized by the efficient cleavage in the peptides, including (Leu,Phe,Met,Val)-Gln $\downarrow$ (Ser,Ala,Gly) sequences (the cleavage site is indicated by $\downarrow)$, and the crystal structures have revealed a remarkable degree of conservation of the substrate- 
a

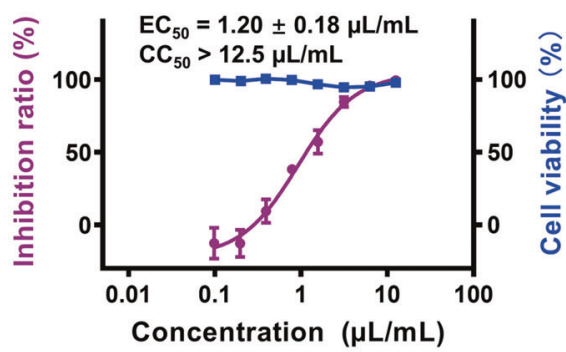

C

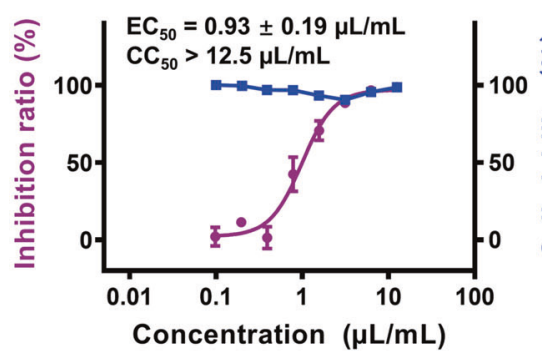

e

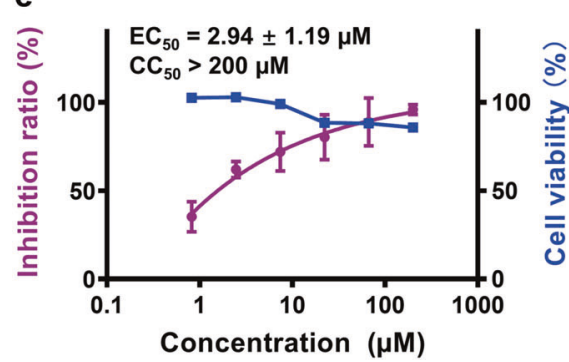

b

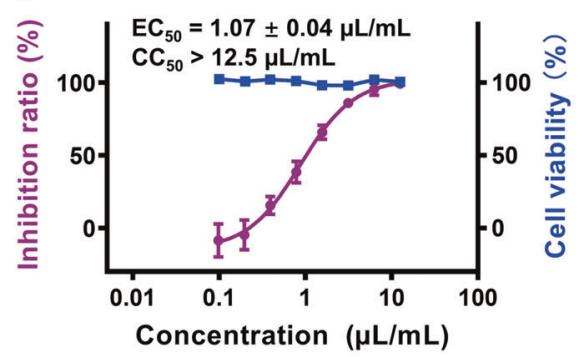

d

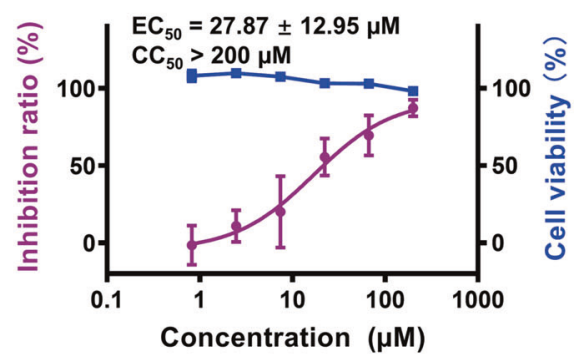

Fig. 5 Antiviral activities and cytotoxicities of Shuanghuanglian oral liquids, baicalin and baicalein. a-c Antiviral activities and cytotoxicities of the three Shuanghuanglian oral liquids, (d) baicalin, and (e) baicalein against SARS-CoV-2 in Vero E6 cells. Cells were infected with SARS-CoV-2 at a multiplicity of infection (MOI) of 0.01 in the presence of different concentrations of oral liquids, baicalin or baicalein for $48 \mathrm{~h}$. Viral yield in the cell supernatant was then quantified by qRT-PCR. All data are shown as mean \pm SD.

binding sites, particularly for the crucial S1/S2 subsites $[8,35,36]$. Accordingly, substrate analogs or mimetics attached to a chemical warhead targeting the catalytic cysteine have been designed as peptidomimetic inhibitors of 3CLpros with a covalent mechanism of action [7]. A series of diamide acetamides acting as noncovalent SARS-CoV 3CLpro inhibitors and their binding modes examined by crystal structures have been reported, but they are more or less peptidomimetic inhibitors, and these compounds have not been continuously developed [37]. Although several other small molecules have been declared 3CLpro inhibitors, a solid validation of their binding with 3 CLpros by ITC or complex structure determination is lacking [38, 39]. Herein, we identified baicalin and baicalein as the first class of noncovalent, nonpeptidomimetic inhibitors of SARS-CoV-2 3CLpro by an enzymatic assay in combination with the ITC, ESI-MS and X-ray protein crystallography. The binding mode of baicalein with the protease revealed by the crystal structure demonstrates that a unique protein-ligand interaction pattern is utilized by baicalein to block the proteolytic activity of SARS-CoV-2 3CLpro. Moreover, with an LE of $0.37 \mathrm{kcal} / \mathrm{mol}$, baicalein is the most efficient binder of 3 CLpros known to date. The simple chemical scaffold, unique mode of action and encouraging antiviral activity in vitro, coupled with the favorable safety data from clinical trials studies described below, emphasize that baicalein is a good candidate for the development of critically needed anticoronaviral drugs.

The roots of $S$. baicalensis Georgi (Huangqin in Chinese) are frequently used in TCM for the prophylaxis and treatment of hepatitis, atherosclerosis, hypertension, hyperlipidemia, type 2 diabetes, dysentery, ulcerative colitis, and other respiratory disorders [40-42]. Baicalin and baicalein are two major bioactive ingredients extracted from $S$. baicalensis Georgi, and show antioxidant, anti-inflammatory, antithrombotic, antidyslipidemic, antidiabetic, and hepatoprotective activities, although their biological targets remain a mystery [42]. In the present study, the inhibition of the crucial 3CLpro of SARS-CoV-2 by baicalin and baicalein is revealed for the first time, demonstrating the potential of these two bioflavonoids as anticoronaviral agents. In addition, baicalin tablets have been used as an adjuvant therapy for the treatment of acute, chronic, or persistent hepatitis in China. Single oral doses of $100-2800 \mathrm{mg}$ of baicalein are safe and well tolerated by healthy subjects (clinical trials registration number: CTR20132944) [43]. Although the plasma concentration of baicalein in vivo after oral administration is low, an inhalation route provides an alternative solution because intratracheal administration of baicalein could significantly increase their target tissue distribution (Supplementary Fig. S8). Furthermore, a randomized, double-blind, placebo-controlled, multicenter phase II clinical trial on the effectiveness and safety of baicalein tablets in the treatment of improving other aspects of healthy adults with influenza fever is underway (clinical trials registration number: CTR20182427 and NCT03830684). These favorable safety data together with the potent inhibitory activities in enzymatic and cell-based assays make it worthwhile to develop baicalin and baicalein into clinical agents, particularly for COVID-19 treatment. 


\section{CONCLUSION}

In summary, three global pandemics, SARS, MERS, and COVID-19, have raised great awareness about the increasing risks of highly pathogenic CoV infections in humans or animals and call for the continuous development of efficacious anticoronaviral drugs. Herein, the potential treatment of COVID-19 by Shuanghuanglian preparations as well as two of its bioactive ingredients, baicalin and baicalein, which have good drug-like properties, has been investigated in vitro. Our findings lay a strong foundation for in vivo and clinical trials studies. More importantly, our crystal structure of baicalein-bound SARS-CoV-2 3CLpro is the first demonstration of the $3 C$ Lpro reversibly inhibited by a small molecule, or even a fragment of one, derived from TCM, providing a good example as well as an ideal lead for the design of new and versatile classes of inhibitors against 3CLpros. Overall, the present study provides a good example for exploring the in vitro potency of Chinese traditional patent medicines and identifying bioactive ingredients toward a specific target, and adds to the evidence supporting the clinical potential of Shuanghuanglian oral liquids as well as two natural products for COVID-19 treatment.

\section{ACKNOWLEDGEMENTS}

The authors sincerely thank Prof. Zi-he Rao and Prof. Hai-tao Yang for kindly providing the initial protein sample as well as substrate for the enzymatic assay of 3CLpro. We also thank the staff from beamlines BL17U1 and BL18U1 at Shanghai Synchrotron Radiation Facility. This work was supported by the National Key R\&D Program of China (nos. 2020YFC0841400, 2017YFB0202604, and 2016YFA0502301), the National Natural Science Foundation of China (nos. 91953000 and 21877122), the International Partnership Program of Chinese Academy of Sciences (no. 153631KYSB20170043), Chinese Academy of Engineering and Jack Ma Foundation (no. 2020-CMKYGG-05), and Science and Technology Commission of Shanghai Municipality (no. 20431900200).

\section{AUTHOR CONTRIBUTIONS}

$\mathrm{HXS}, \mathrm{WFZ}, \mathrm{HX}$, and $\mathrm{HCH}$ parepared the protein sample, performed the enzymatic assay and the ITC measurement. HXS, WFZ, and MJL dertermined the crystal structure. SY and CQK parepared the compounds, determined the content of four compounds in Shuanghuanglian preparations and characterized 28 compounds in Shuanghuanglian oral liquids. JL and CQK carried out the mass spectroscopy experiments and the different administration routes of baicalin and baicalein. WJS, YW, LKZ, and GFX performed antiviral activities measurement in cells. MNG, KQY, HL, JSS, WT, LN, DWW, and JPZ helped with data analysis and interpretation. HLJ, YCX, YY, and $F B$ initiated the project and supervised the research. YCX wrote the paper with input from all co-authors.

\section{ADDITIONAL INFORMATION}

The online version of this article (https://doi.org/10.1038/s41401-020-0483-6) contains supplementary material, which is available to authorized users.

Competing interests: The authors declare no competing interests.

\section{REFERENCES}

1. Zumla A, Chan JFW, Azhar El, Hui DSC, Yuen KY. Coronaviruses-drug discovery and therapeutic options. Nat Rev Drug Discov. 2016;15:327-47.

2. de Wit E, van Doremalen N, Falzarano D, Munster VJ. SARS and MERS: recent insights into emerging coronaviruses. Nat Rev Microbiol. 2016;14:523-34.

3. Li Q, Guan X, Wu P, Wang X, Zhou L, Tong Y, et al. Early transmission dynamics in Wuhan, China, of novel coronavirus-infected pneumonia. N Engl J Med. 2020;382:1199-207.

4. Chan JF, Yuan S, Kok KH, To KK, Chu H, Yang J, et al. A familial cluster of pneumonia associated with the 2019 novel coronavirus indicating person-toperson transmission: a study of a family cluster. Lancet. 2020;395:514-23.

5. Zhou $P$, Yang XL, Wang XG, Hu B, Zhang L, Zhang W, et al. A pneumonia outbreak associated with a new coronavirus of probable bat origin. Nature. 2020;579:270-3.

6. Dong E, Du H, Gardner L. An interactive web-based dashboard to track COVID-19 in real time. Lancet Infect Dis. 2020;20:533-4.
7. Pillaiyar T, Manickam M, Namasivayam V, Hayashi Y, Jung SH. An overview of severe acute respiratory syndrome-coronavirus (SARS-CoV) $3 \mathrm{CL}$ protease inhibitors: peptidomimetics and small molecule chemotherapy. J Med Chem. 2016;59:6595-628.

8. Yang $\mathrm{H}$, Xie W, Xue X, Yang K, Ma J, Liang W. Design of wide-spectrum inhibitors targeting coronavirus main proteases. PLoS Biol. 2005;3:e324.

9. Dai W, Zhang B, Jiang XM, Su H, Li J, Zhao Y, et al. Structure-based design of antiviral drug candidates targeting the SARS-CoV-2 main protease. Science. 2020;368:1331-5.

10. Jin Z, Du X, Xu Y, Deng Y, Liu M, Zhao Y, et al. Structure of M(pro) from COVID-19 virus and discovery of its inhibitors. Nature. 2020;582:289-93.

11. Wang $\mathrm{YH}, \mathrm{Xu} \mathrm{KJ}$, Jiang WS. Experimental and clinical study of shuanghuanglian aerosol in treating acute respiratory tract infection. Zhongguo Zhong Xi Yi Jie He Za Zhi. 1995;15:347-50.

12. Guo J, Song DR. Research progress in pharmacological action, clinical application and adverse reactions of Shuanghuanglian. Chin J Clin Ration Drug Use. 2017;21:161-3. Chinese

13. Gao Y, Hou R, Han Y, Fei Q, Cai R, Qi Y. Shuang-Huang-Lian injection induces an immediate hypersensitivity reaction via C5a but not IgE. Sci Rep. 2018;8:3572.

14. Chen HL, Liu XJ, Gao Y, Zhao BN. Pharmacological activity and quality evaluation method of Shuanghuanglian oral liquid. J LiaoNing Univ TCM. 2016;18:161-3. Chinese

15. Guan SN, Wu D. Research progress in clinical application of Shuanghuanglian oral liquid. Inf Tradit Chin Med. 2005;22:38-9. Chinese

16. Ma $Q$, Liang $D$, Song $S, Y u$, Shi $C$, Xing $X$, et al. Comparative study on the antivirus activity of Shuang-Huang-Lian injectable powder and Its bioactive compound mixture against human adenovirus III in vitro. Viruses. 2017;9:79.

17. Law $A H$, Yang $C L$, Lau AS, Chan GC. Antiviral effect of forsythoside A from Forsythia suspensa (Thunb.) Vahl fruit against influenza A virus through reduction of viral M1 protein. J Ethnopharmacol. 2017;209:236-47.

18. Ding Y, Cao Z, Cao L, Ding G, Wang Z, Xiao W. Antiviral activity of chlorogenic acid against influenza $A(\mathrm{H} 1 \mathrm{~N} 1 / \mathrm{H} 3 \mathrm{~N} 2)$ virus and its inhibition of neuraminidase. Sci Rep. 2017;7:45723.

19. Guo YP, Lin LG, Wang YT. Chemistry and pharmacology of the herb pair Flos Lonicerae japonicae-Forsythiae fructus. Chin Med. 2015;10:16.

20. Tang $Y$, Wang Z, Huo C, Guo X, Yang G, Wang M, et al. Antiviral effects of Shuanghuanglian injection powder against influenza $A$ virus $H 5 N 1$ in vitro and in vivo. Microb Pathog. 2018;121:318-24.

21. Zhang FX, Xie ZN, Tang XY, Li C, Li M, Yao ZH, et al. A combination of representative compounds, metabolism platform and diagnostic extraction strategy for characterization of metabolites of Shuang-Huang-Lian oral liquid in vivo by ultra-performance liquid chromatography coupled with time-of-flight mass spectrometry. J Pharm Biomed Anal. 2018;155:216-34.

22. Liang J, Yang Q, Xia YG, Yang BY, Kuang HX. HPLC fingerprints of Shuanghuanglian oral liquids. Acta Chin Med Pharmacol. 2013;41:24-6. Chinese

23. Ghosh AK, Takayama J, Aubin Y, Ratia K, Chaudhuri R, Baez Y, et al. Structurebased design, synthesis, and biological evaluation of a series of novel and reversible inhibitors for the severe acute respiratory syndrome-coronavirus papain-like protease. J Med Chem. 2009;52:5228-40.

24. Pedro L, Van Voorhis WC, Quinn RJ. Optimization of electrospray ionization by statistical design of experiments and response surface methodology: proteinligand equilibrium dissociation constant determinations. J Am Soc Mass Spectrom. 2016;27:1520-30.

25. Wang QS, Zhang KH, Cui Y, Wang ZJ, Pan QY, Liu K, et al. Upgrade of macromolecular crystallography beamline BL17U1 at SSRF. Nucl Sci Tech. 2018;29:68.

26. Minor W, Cymborowski M, Otwinowski Z, Chruszcz M. HKL-3000: the integration of data reduction and structure solution - from diffraction images to an initial model in minutes. Acta Crystallogr D. 2006;62:859-66.

27. Mccoy AJ, Grosse-Kunstleve RW, Adams PD, Winn MD, Storoni LC, Read RJ. Phaser crystallographic software. J Appl Crystallogr. 2007;40:658-74.

28. Emsley P, Cowtan K. Coot: model-building tools for molecular graphics. Acta Crystallogr D. 2004;60:2126-32.

29. Adams PD, Grosse-Kunstleve RW, Hung LW, loerger TR, McCoy AJ, Moriarty NW, et al. PHENIX: building new software for automated crystallographic structure determination. Acta Crystallogr D. 2002;58:1948-54.

30. Liu J, Cao RY, Xu MY, Wang X, Zhang HY, Hu HR, et al. Hydroxychloroquine, a less toxic derivative of chloroquine, is effective in inhibiting SARS-CoV-2 infection in vitro. Cell Discov. 2020;6:16.

31. Kenny PW. Comment on the ecstasy and agony of assay interference compounds. J Chem Inf Model. 2017;57:2640-5.

32. Woods LA, Dolezal O, Ren B, Ryan JH, Peat TS, Poulsen SA. Native state mass spectrometry, surface plasmon resonance, and x-ray crystallography correlate strongly as a fragment screening combination. J Med Chem. 2016;59:2192-204. 
33. Tan JZ, Verschueren KHG, Anand K, Shen JH, Yang MJ, Xu YC, et al. PH-dependent conformational flexibility of the SARS-CoV main proteinase (M-pro) dimer: Molecular dynamics simulations and multiple X-ray structure analyses. J Mol Biol. 2005;354:25-40.

34. Ni L, Zhou L, Zhou M, Zhao J, Wang DW. Combination of the western medicine and the Chinese patent medicine in treating family cases of COVID-19 in Wuhan. Front Med. 2020;14:210-4.

35. Anand K, Ziebuhr J, Wadhwani P, Mesters JR, Hilgenfeld R. Coronavirus main proteinase (3CLpro) structure: basis for design of anti-SARS drugs. Science. 2003;300:1763-7.

36. Muramatsu T, Takemoto C, Kim YT, Wang H, Nishii W, Terada T, et al. SARS-CoV $3 \mathrm{CL}$ protease cleaves its $\mathrm{C}$-terminal autoprocessing site by novel subsite cooperativity. Proc Nat Acad Sci U S A. 2016;113:12997-3002.

37. Jacobs J, Grum-Tokars V, Zhou Y, Turlington M, Saldanha SA, Chase P, et al. Discovery, synthesis, and structure-based optimization of a series of $\mathrm{N}$-(tertbutyl)-2-(N-arylamido)-2-(pyridin-3-yl) acetamides (ML188) as potent noncovalent small molecule inhibitors of the severe acute respiratory syndrome coronavirus (SARS-CoV) 3CL protease. J Med Chem. 2013;56:534-46.
38. Chen LR, Wang YC, Lin YW, Chou SY, Chen SF, Liu LT, et al. Synthesis and evaluation of isatin derivatives as effective SARS coronavirus $3 \mathrm{CL}$ protease inhibitors. Bioorg Med Chem Lett. 2005;15:3058-62.

39. Zhang J, Huitema C, Niu C, Yin J, James MN, Eltis LD, et al. Aryl methylene ketones and fluorinated methylene ketones as reversible inhibitors for severe acute respiratory syndrome (SARS) 3C-like proteinase. Bioorg Chem. 2008;36:229-40.

40. Fang $P, Y u$ M, Shi $M$, Bo $P, G u X$, Zhang Z. Baicalin and its aglycone: a novel approach for treatment of metabolic disorders. Pharmacol Rep. 2020;72:13-23.

41. Liang S, Deng X, Lei L, Zheng Y, Ai J, Chen L, et al. The comparative study of the therapeutic effects and mechanism of baicalin, baicalein, and their combination on ulcerative colitis rat. Front Pharmacol. 2019;10:1466.

42. Dinda B, Dinda S, DasSharma S, Banik R, Chakraborty A, Dinda M. Therapeutic potentials of baicalin and its aglycone, baicalein against inflammatory disorders. Eur J Med Chem. 2017;131:68-80.

43. Li M, Shi A, Pang H, Xue W, Li Y, Cao G, et al. Safety, tolerability, and pharmacokinetics of a single ascending dose of baicalein chewable tablets in healthy subjects. J Ethnopharmacol. 2014;156:210-5. 